\title{
O livro
}

Vanderney Lopes da Gama ${ }^{1}$

Todos diziam que ele era um homem só e evasivo. Fugia de tudo e de todos. Vivia enfurnado em seu apartamento moderno na zona sul do Rio de Janeiro em busca de criar ou matar mais uma quase ficção. Talvez fosse isso... O que sabemos realmente é que ele nunca tinha sido escritor antes do fato que aconteceu em um dia chuvoso de um inverno quente no Rio. Sobre sua escrivaninha foram encontradas umas letras que, por mais fantásticas que parecessem, demonstravam um universo perturbado e confuso daquele homem...

Ontem estava um dia frio. Não que a frieza daquele momento me incomodasse. Já me acostumei a conviver com as temperaturas baixas. O que mais me assustava, às vezes, era a frieza do ser humano. A gelidez dos corações e mentes apavora-me como se fosse uma criança que vagueia circundada por monstros terriveis, próprios da infância e da imaginação de um louco ou de um lunático.

\footnotetext{
${ }^{1}$ Mestrando em Literatura Brasileira na Universidade Estadual do Rio de Janeiro sob a orientação do Professor Doutor Flavio García.
} 
Não imaginava que depois de duas ou três taças de um bom e delicioso vinho teria um encontro tão inesperado que mexeria com minhas convicções.

Estava sozinho em casa quando, sem esperar por ninguém, a campainha de meu apartamento tocou insistentemente. Olhei pelo olho mágico e nada vi. Voltei e sentei no sofá, observando a taça que brilhava em minhas mãos e de onde saía o aroma do vinho, envelhecido tempo o bastante para saber que estava na hora de...

Neste momento, novamente soou a campainha e fui à porta. Bisbilhotei pelo olho mágico e nada. Abri a porta e nada novamente... Devo confessar que minha ida até a porta foi um tanto quanto difícil, pois o vinho era bom e a garrafa já não estava cheia. Virei e fui em direção ao centro da sala, deixando atrás de mim a incerteza do fato acontecido e a porta escura que se afastava longa e lentamente enquanto pensava no vinho e nessa confusão que agitava meus pensamentos.

Chegando ao centro de minha sala escura, julguei ter visto, sentado em meu sofá verde-escuro, um certo homem que, sem que perguntasse, disse-me que se chamava Carlos.

Em um primeiro momento, acreditei estar tendo uma alucinação devido à quantidade de vinho que havia ingerido. Depois, pensei que talvez estivesse tendo um surto esquizofrênico e criando uma possível realidade para que enfim pudesse sair de meu isolamento completo provocado por uma vida de ausências e sensações estranhas e inacabadas... Achei melhor, então, ir ao banheiro e lavar o rosto para 
ver se espantava os fantasmas que o álcool trazia aos meus olhos ou à imaginação... não sei ao certo... O relógio marcava 01 h26min.

Quando voltei, sentei no sofá em frente ao dele e conversamos a noite toda como se já nos conhecêssemos há muitos anos. Falávamos sobre tudo, inclusive de um livro que Carlos disse ter escrito há alguns anos, quando ainda era um jovem rapaz recém formado. Disse-me ele que o livro narrava umas histórias estranhas e assustadoras...

As horas passaram, adormecemos e, no dia seguinte, acordei cedo e sozinho para ir à padaria da esquina comprar o pão quente das manhãs cariocas e ler o jornal com as últimas notícias...

O fato que mais me chamou a atenção naquela manhã cinzenta e chuviscosa foi justamente uma manchete no jornal que anunciava a morte de um escritor. A matéria relatava os detalhes de sua morte e a hora exata do fato... Lembrei-me de que muitos detalhes descritos na reportagem foram ou pareciam ter sido narrados por aquele homem que se encontrava em meu apartamento na noite anterior...

Ao olhar a hora do falecimento do escritor, percebi que fora a mesma do momento em que fui ao banheiro lavar o rosto... Comecei a questionar os acontecimentos e duvidar de minhas experiências vividas naquela noite estranha. Corri para casa como se buscasse uma prova daquela existência de minha sanidade ou insanidade... não sei! Revirei a sala, o quarto, o banheiro. Procurei por todos os cantos da casa. Nada encontrei... Terminei de ler a notícia do jornal e fiquei observando o tempo e os passantes da rua abaixo de meu apartamento.

Não notei o avançar das horas. 
Três horas da tarde... na bagunça em que ficou meu apartamento, encontrei umas correspondências fechadas de pessoas que não via há muito tempo... Nunca gostei de ler cartas... até as cobranças chegavam e quando via já haviam vencido há meses e ficavam assim mesmo... Cansei de pagar os juros de meu isolamento...

Vinte minutos depois, $15 \mathrm{~h} 20 \mathrm{~min}$, o interfone toca... Era o carteiro dizendo que havia uma correspondência que eu precisava assinar para receber. Desci, vacilante, os degraus da escada, como se contasse cada um deles, tentando achar na contagem ou nos degraus alguma resposta para meus questionamentos e minhas dúvidas.

Lá estava o homem do correio, vestido de amarelo, como sempre, segurando a encomenda. Sorriu-me azedamente (acredito que pela demora), assinei o papel e recebi o volume. Subi ansioso e calmo. Abri o pacote e ali estava, em minhas mãos, um livro chamado Simplesmente Fantástico, escrito por um Carlos Carneiro.

O sobrenome acendeu-me as lembranças e vi o Carlos de outrora sentado em minha sala, conversando comigo na noite anterior a tudo.

Tive remorsos por não ter lembrado naquele momento do Carneiro dos velhos tempos da faculdade. Dentro do livro havia umas cópias de cartas que ele enviou para mim, mas voltaram ou não foram respondidas. Guardei as cartas e esqueci os remorsos. Comecei a ler os contos daquele livro incomum e, a cada história lida, tive a sensação de que eu mesmo não passava apenas de mais uma personagem das histórias escritas por Carlos... 
Ao terminar de ler, estava eu sentado em uma sala desconhecida, conversando com uma mulher que acreditava conhecer de algum lugar...

Falávamos sobre as histórias daquele livro..., mas ela olhava para mim da mesma forma como eu olhara para Carlos naquela noite... Percebi então que tudo iria se repetir e que o livro era, na verdade, um convite para registrar em suas páginas malditas a sua última história de vida.

Foi dessa forma que aquele homem simplesmente desapareceu das vistas de todos... não sabemos se a maldição do livro que suga vidas é uma verdade ou se o solitário carioca cansou de tudo e sumiu, deixando para trás as interrogações de uma existência triste e confusa; sem se preocupar em dar alguma explicação sobre os escritos que foram encontrados em cima de sua escrivaninha... 


\section{Apenas mais uma história}

Meu nome é Carolina.

$\mathrm{Na}$ verdade, sou uma pessoa que acorda todos os dias pela manhã e procura ter uma vida tranquila e calma, assim como deve ser a de uma solitária e simples mulher moderna.

Não tenho vícios e manias.

Minha maior e única crença estava fundamentada no homem. Cheguei até a ler umas ideias de uns filósofos sobre a literatura contemporânea... Adoro ler. Existem escritores impagáveis em nossas letras... Viajo muito. Internet e academia de ginástica são cansativas e chatas... Pessoas artificiais falam de coisas desinteressantes... Não tenho muita paciência para lidar com elas. Prefiro a leitura. Com ela estabeleço novas realidades que me fazem bem. Comunico-me com um universo diverso do meu, mas mesmo assim surpreendente e fascinante. Como não ler As academias de Sião? Ou então Um moço muito branco? São contos que nos remetem a um mundo fantástico onde tudo e nada são apenas duas palavras...

Mais adiante, você que me lê (ou por curiosidade ou por se interessar por este relato breve de meus dias); você que me lê verá o porquê de minhas convicções e crenças terem mudado de uns tempos para cá... 
Moro em uma casa simples, ampla e confortável. Gosto de andar pelas ruas desertas e gélidas de Miguel Pereira, principalmente nas noites de julho e agosto. Na rua em que moro, lá no final, há uma belíssima igreja com um sino renitente que costuma invadir as casas com sua presença sonora... Dia e noite ouve-se o badalar ao longe, repicando uma cantiga triste, estranha e, às vezes, assustadora... Ao lado, há uma pequena venda onde os moradores compram o pão quente de todas as manhãs. É uma vida tranquila e normal.

Trabalho com filmagens e fotografias. Sempre gostei de explorar novidades complexas que as luzes e as lentes de minha máquina digital conseguem captar nos momentos mais inoportunos e inusitados que possamos imaginar. E foi exatamente em uma dessas explorações que um dia algo estranho aconteceu e mudou a calmaria dos meus dias.

Acho que o leitor começa a ter uma pequena ideia do que está por vir. Não é dificil imaginar que em algum momento de minha pacata e simples vida de cidade pequena, alguma coisa mudaria de tal forma que mexeria inclusive com minha maneira de ver a vida (ou quem sabe a morte?).

Domingo. O ano era 2007. A data... não lembro. Sei que foi em junho!

Nesse dia chovia pouco, mas insistentemente. Dia frio e preguiçoso. Fiquei em casa cuidando de minhas coisas. Gostava de deixar a câmera ligada, gravando o ambiente ao meu redor. Fazia isso até mesmo quando não estava em casa ou quando era noite. Loucuras! 
Nesse dia, tinha umas fotos para revelar e, depois, queria fazer algumas experiências com umas filmagens que realizara na semana anterior. Emoldurando todo o cenário de chuva, de frio e solidão, lá vinha adentrar o sossego de minha confortável casa o som longínquo daquele sino que mais parecia prenunciar algum mal iminente do que qualquer outra coisa benéfica.

Distraída, nem percebi que a campainha de minha casa soou duas vezes... (acho que sim...). Na terceira vez, fui à porta para abri-la e ver quem me incomodava naquele dia impróprio para visitas.

É engraçado como um percurso tão pequeno como o do quarto à porta da sala serve para reviver lembranças de outrora. Pessoas, coisas, momentos e situações criaram vida em meu pensamento e confesso que senti saudades... uma espécie de nostalgia medrosa de um tempo em que minha vida social era mais agitada e povoada de pessoas... Acredito que nessas lembranças encontrei uns amigos que há muito não via... Que lástima! Acho que todos passaram!

Abri a porta e fiquei surpresa com a visita. Ângela. Uma de minhas melhores amigas dos tempos de escola. Faziamos muitas besteiras juntas. Éramos confidentes! No entanto, naquele primeiro momento, ali, parada em minha porta, diante de meus olhos, ela parecia triste e ao mesmo tempo suave. Não perdi tempo e pedi que entrasse e que se sentasse. Peguei umas bebidas que tinha guardado em uma estantebar, acrescentei gelo e enchi os copos. Lembro que bebia com naturalidade... Mas, depois do quarto copo, talvez, tive a impressão de 
que Ângela evitava a bebida. Talvez fosse isso! Não tenho certeza agora! A verdade é que tudo parecia cansativamente novo e melancólico.

Conversávamos e relembrávamos momentos inesqueciveis daqueles tempos que deixaram saudades boas e vivas. Sabia que a visita era indesejada, mas, ao mesmo tempo, gostava de estar ali e falar de coisas que faziam parte de um passado distante: a cola na prova, as fugidas de sala de aula para um show do Lulu Santos, os porres de vinho e o namorico com o Carlos... Bons tempos eram aqueles!

Carlos foi um rapaz da faculdade de letras que conheci. Alguns diziam que ele era um cara meio estranho. Nada! Só era diferente e bastante introspectivo. No meio de um bando de mulheres faladeiras, ele ficava na dele só me olhando e disfarçando o olhar quando eu o encarava... Não sei o que houve com ele. Acabou o curso e o namorico também. Formamos e nunca mais ouvi falar daquele rapaz. Faz parte do passado!

Ângela, em alguns momentos de nossas conversas, parecia que queria me dizer algo, mas não encontrava meios ou palavras para fazêlo. Julguei que estivesse com algum problema pessoal e que não se sentia bem em se abrir comigo depois de tantos anos de distância. Deixei pra lá e o tempo passou. Como sempre, ele avança e nem percebemos.

Quando dei por mim, já era noite e eu estava dormindo no sofá, sozinha. 
Dei um pulo e fui ver se minha amiga ainda estava na casa. Ao chegar à porta do quarto, lá estava ela. Parecia deitada e dormindo profundamente.

Não sei o porquê do desejo, mas precisava ler um poema de Bandeira. Peguei minha antologia e, furtivamente, abri a ermo as páginas do livro, pensando: onde cair, lerei! Li o poema e fiquei aliviada e feliz com a familiaridade da visão do quarto com as linhas do texto.

Ângela que me perdoe!

Fui dormir. Já passava das duas da madrugada e eu estava cansada e meio tonta.

Não era mais tão forte para bebidas! Fui para o quarto ao lado.

No dia seguinte acordei com uma tremenda dor de cabeça. Fui ao quarto, mas estava vazio. A cama havia sido feita... Nem parecia que alguém dormira ali. Imediatamente pensei que minha inoportuna visita saiu como chegou: sem avisar...

O dia começou e minha rotina me fez esquecer as conversas e a bebedeira. Cheguei a questionar algumas coisas comigo mesma sobre aquela noite, mas balancei firmemente a cabeça e tratei de esquecê-las. Não havia razão alguma para levantar hipóteses ou dúvidas...

Os minutos, as horas e os dias se passaram e tudo parecia voltar ao seu estágio normal. Nem lembrava mais daquele dia chuvoso em que Ângela chegou a minha casa tão inesperadamente. Posso dizer que minha pacata vida quase voltou ao normal.

Vasculhando minhas filmagens, encontrei vários trechos de fitas que simplesmente não possuíam imagem. Só havia uns rabiscos e um 
chiado chato que me obrigava a abaixar completamente o volume da televisão. Às vezes, ficava algumas horas assistindo àquilo como se quisesse encontrar algo que nem eu mesma sabia o que era.

Nada!

Nunca encontrava nada!

Há coisas que acontecem na vida do ser humano que são simplesmente inexplicáveis. Desde o nascimento até a morte, a vida do homem é repleta de fatos comuns e corriqueiros que são rapidamente apagados de nossa memória pela ação corrosiva do tempo. Não percebemos o quanto somos afetados pelas coisas mais ínfimas. Só nos damos conta quando algo ou alguém decide chamar nossa atenção para, quem sabe, ver até que ponto estamos mergulhados na vida. De vez em quando é melhor não pensar e nem sentir, apenas existir já faz de nós uma peça importante em todo esse quebra-cabeça.

Foi numa manhã de primavera. Dia belo e agradável. Não chovia!

Estava eu sentada na varanda de minha casa observando as flores, os pássaros e toda a arquitetura natural do lugar, quando senti um daqueles ventos frios que sobem dos pés à cabeça. Achei incomum em um dia como aquele sentir tal sensação. Não liguei e continuei ali sentada e encantada com tudo.

Ao longe, bem devagar, quase como uma sombra ou um vulto, a figura de um homem se mostrava e se aproximava cada vez mais do lugar em que eu estava. Parecia que andava rápido em alguns momentos e em outros tinha a impressão de que deslizava sobre o chão como se flutuasse lentamente em minha direção. 
Era um homem feito, jovem e bonito. Imediatamente o reconheci. Não poderia esquecer aquele olhar e aquele jeito dos tempos de escola. É claro que naquele olhar, agora, havia uma espécie de súplica; como se, por ele, eu pudesse tatear um mundo desconhecido. O desejo e a timidez dos olhos de outrora cederam lugar a uma eterna aparência de cera fria e sem vida.

Que loucura!

Não entendia nada!

Era o Carlos!

Foi muito bom revê-lo. Ele veio caminhando e parou do lado de fora do muro baixo do meu quintal. Convidei-o para entrar, mas recusou. Disse-me que precisaria ir logo, pois não tinha muito tempo... Não entendi bem o motivo de tanta pressa, mas não insisti. Aceitei a situação e conversamos um pouco sobre coisas do meu presente e sobre o passado dele. Revivemos momentos.

De repente, Carlos olhou para um relógio imaginário no pulso e disse que precisava ir. Tomou a rua e foi. Fiquei observando sua partida e, no horizonte, acompanhei o desaparecimento daquela imagem tão inexata que se desconfigurou no instante em que meus olhos não mais conseguiam discernir o que era aquilo que viam.

Carlos sumiu novamente!

Subitamente, desliguei-me dele e tive a impressão de que o vento, os pássaros e as árvores estavam parados, como se uma quebra no tempo tivesse ocorrido ou estivesse ocorrendo... Não sei explicar. Voltei a olhar para o horizonte, mas nada vi de estranho e, lentamente, todas 
as coisas voltavam ao seu estágio natural. Levantei de onde estava e entrei na casa, pensando que da mesma forma como a visita de Ângela, a de Carlos também me pegou de surpresa e provocou em mim umas dúvidas sobre esses estranhos acontecimentos... A chegada tão repentina deles e a partida mais ainda!

No dia seguinte fui à cidade comprar umas mídias novas para gravar trabalhos encomendados. Na volta, passei na casa de meus pais e peguei os dois para passarem o resto do dia lá em casa comigo. Acho que estava precisando desse contato familiar.

Foi muito bom!

Almoçamos juntos, falamos da vida, da infância e depois, quando já estava um pouco tarde, levei-os de volta para suas casas. As pessoas velhas não gostam de dormir fora de casa... Acham que o lugar mais seguro do mundo é o próprio lar e somente ele... Coisa de velhos!

Ao retornar, peguei minha câmera de filmagem e comecei a procurar os arquivos salvos na memória da máquina para editá-los e, posteriormente, gravá-los definitivamente.

Sempre fiz esse tipo de trabalho e nunca tinha tido nenhuma surpresa até aquele dia.

Fui ao quarto e peguei as mídias novas. Gravei todo material de trabalho e depois fiquei fuçando a máquina para ver o restante dos arquivos salvos. Foi diferente dessa vez! Em alguns momentos das gravações havia muito ruído e não se podia ouvir absolutamente nada que se confundisse com palavra. No entanto, observando as imagens 
cinza que apareciam na tela de meu computador, notei que não havia só uma tela vazia...

Apaguei as luzes e fiquei em completa escuridão para ver se realçava a imagem da tela. Comecei a perceber que em meio a tanta imagem vazia, de vez em quando aparecia uma ou outra que sombreava uma figura qualquer no fundo... Tive a impressão de que conhecia aquelas imagens que se desenhavam vez ou outra na tela do computador, embaçadas pelos rabiscos e traços que surgiam do nada na filmagem.

Fiquei curiosa e iniciei um trabalho investigativo. Primeiro, precisava descobrir quando aquela cena foi gravada. Debrucei-me sobre as máquinas que tinha e, quadro a quadro, fui limpando as cenas para ver algo que direcionasse meu pensamento... Não consegui muita coisa, mas o máximo que obtive de meu esforço foi saber o mês e o ano: junho de 2007. Diante dessa constatação, vieram-me questões insolúveis... Em que dia isso teria sido gravado? Quem era aquela pessoa? Havia uma pessoa ali ou era uma ilusão de meus sentidos? Como gravei aquilo e não percebi antes?

Quase enlouqueci com tantas perguntas sem respostas. Guardei tudo e fui para cama. Passando em frente ao quarto em que Ângela dormiu, lembrei que naquele dia havia deixado a máquina gravando a sala de estar. Lembro-me que quando a visita chegou não desliguei a câmera naquele momento e como havia ficado sob o efeito da bebida só desliguei o equipamento quase no final do dia seguinte. 
No mesmo instante, voltei para o computador e procurava observar com bastante atenção o que passava diante dos meus olhos. Comecei a revirar vários DVDs na busca de algum material parecido com aquele do dia em que Ângela estivera lá em casa. Não encontrei nenhum. Achei estranho e iniciei uma luta com meus sentidos para ver e ouvir as mídias e, juntamente a essa luta, buscava forças para me manter acordada pela madrugada à dentro.

Depois de várias tentativas, consegui isolar alguns sons e imagens que simplesmente me aterrorizaram... Larguei tudo subitamente e confesso que senti um medo que me corria pelas vértebras, arrepiando meu corpo por inteiro. Às quatro horas da madrugada enfim, consegui perceber que a figura que aparecia distorcida naquela filmagem era a de minha colega de escola. Tive a quase plena certeza dessa constatação.

Esse fato não foi o motivo de meu solavanco repentino. Suas palavras é que me perturbaram. Lembro-me de que, naquele dia, parecia que ela queria me dizer algo e eu achava que não conseguia. $\mathrm{Na}$ verdade, tudo o que ela teria dito naquela noite estava ali registrado... Meio confuso, mas, com um bom trabalho de edição, percebiam-se as palavras e a mensagem.

Com uma voz trêmula e distante ela dizia "Estou morta e preciso te pedir perdão". Essas palavras entraram em minha mente tal qual o badalar daquele sino e repicaram em meu interior fazendo estrago pelos mais recônditos vãos por que passou.

Foram inevitáveis os questionamentos. Como estaria morta se naquele dia falei com ela? Estaria eu tendo alucinações? Foi o efeito da 
bebida? Ou estou enlouquecendo realmente? Olhei de novo o material na ânsia de me enganar, mas a cada nova olhada ratificava mais ainda minhas suspeitas: parecia realmente que aquela mulher na tela de meu computador era minha amiga e que me dizia o que dizia. Tudo isso é extremamente bizarro! Pensei, desligando todo o maquinário.

Fui para o meu quarto, mas não dormi. Fiquei deitada e pensando em tudo. Por que ela precisava de meu perdão? Por que reapareceu depois de tanto tempo? As perguntas e os pensamentos foram tão cansativos que me levaram, aos poucos, a pegar no sono... Dormi!

No dia seguinte, refeita do susto, abri os olhos e, ainda deitada, imediatamente me lembrei de Carlos. Não sabia exatamente porque, mas foi a primeira coisa que me veio à mente. Iniciei o dia com dúvidas: Haveria alguma relação entre o surgimento dele e de Ângela? O que ela queria-me dizer tinha a ver com ele? Por que os dois apareceram e desapareceram tão repentinamente?

Decidi que deveria entender esses mistérios. Direcionei minhas energias para isso e fui buscar respostas. Analisei todos os arquivos que tinha gravado nas mídias e no computador. Encontrei, para minha surpresa, novos pedaços de filmagens em que não uma, mas, agora, duas imagens se contorciam em meio ao universo cinza e barulhento das gravações. Naquele dia, tive uma convicção insustentável e inexplicável de que aqueles dois seres gravados eram, na verdade, Carlos e Ângela. A partir daí, comecei a fazer umas investigações para entender o que se passava. 
Primeiro, procurei saber o que havia acontecido com eles. Fui a casa em que minha amiga havia morado nos tempos de escola. Não achei os pais. Somente amigos e vizinhos estavam por lá. Disseram-me que os pais dela haviam morrido há anos e que ninguém entendia o que aconteceu com aquela menina alegre e cheia de vida dos tempos de adolescência. Todos diziam que depois da morte de um namorado que Ângela teve logo depois de formada, ela nunca mais conseguiu ser a mesma pessoa alegre e feliz.

Os amigos e vizinhos mais próximos dela diziam que as pessoas invejosas ou inimigas falavam muita mentira sobre o destino da moça. Muitos caluniavam a jovem adolescente sem ao menos ter tido qualquer tipo de contato ou convivio com ela. Havia até um comentário correndo na cidade que dizia que ela teria assassinado o namorado por ciúmes. A verdade é que ninguém pode confirmar ou desmentir tais boatos. A única coisa de que todos tinham certeza é que ela foi encontrada morta em seu apartamento, sentada no sofá de sua sala de estar como se estivesse lendo um livro de histórias incomuns... Esse livro teria sido escrito pelo namorado Carlos, um jovem e iniciante escritor que viveu e desapareceu de forma bastante estranha e inusitada. Até hoje, as pessoas dizem que não sabem do paradeiro do rapaz... Afirmam que ele simples e misteriosamente sumiu da vista de todos.

Todas essas informações me deixaram perturbada e confusa. Admito que senti uma certa felicidade contida em saber que ela havia morrido. Acho que foi meu instinto de mulher enganada: então o 
namoro dela com o Carlos teria sido o motivo de eles terem se afastado de mim?

Por que não me contaram? Afinal de contas, não havia mais nada entre mim e ele! Não ficaria chateada se soubesse por ela... Mas ficar sabendo dessa forma e sem ao menos poder agredi-la, xingá-la ou simplesmente evitá-la me deixava enraivecida, querendo algo pior do que a morte para os dois... Esses pensamentos passaram por mim e prosseguiram adiante como um vento forte que levanta as folhas adormecidas no fundo de uma caverna desabitada. Deixei-os pra lá e me concentrei no que havia acontecido antes de eu chegar ali àqueles fatos.

Não quero imaginar que o amor é ferida que dói e não se sente. Quem pensa assim, com certeza não saberia definir toda uma existência. Seriam meus sentimentos de tristeza, solidão e angústia uma forma inacabada de um amor não realizado? Meu desejo pela nostalgia de um lugar tão distante dos centros urbanos seria uma manifestação inconsciente de minhas emoções infelizes de outrora? Esse comportamento introspectivo que assumi em vários momentos de minha vida não seria uma forma calada de manifestar a dor de um sentimento afogado em um mar de incertezas e desconfianças? Então, Camões que me perdoe, mas acredito que senti todas as dores dele!

A frase de Ângela não me saía da mente... Por que a necessidade de me pedir perdão? Seria pelo Carlos? Acho que não... era muito pouco! Afinal de contas, quando eles começaram a namorar já haviamos 
terminado o namoro. Foi depois da formatura. Então, qual era o motivo dessa súplica póstuma?

Procurei por respostas, mas não as achei. Deveria estar uns dois ou quatro meses tentando solucionar aquele mistério que invadira minha vida. Por mais que me perguntasse quais eram os motivos de meu ato generoso de perdoá-la, não encontrava nada que ligasse uma coisa à outra. Ficava confusa a cada nova descoberta, mas não me levava a lugar algum.

O tempo foi passando e... sabemos que ele tem o poder de amarelar as mais alvas folhas da vida. Deixei a poeira assentar e toquei minha vida novamente como se nada tivesse acontecido. Passaram-se dias, semanas, meses...tudo voltou a sua rotina normal e eu esqueci a agitação daquelas buscas vãs!

Lembro-me como se fosse hoje... No trigésimo dia, do mês de junho de 2008, recebi em minha casa uma correspondência inesperada de um remetente cujo nome era-me dificil de ler... Esforcei-me em decifrá-lo, mas não consegui. Desisti!

No interior do pacote, havia um livro e junto com ele um bilhete de uma pessoa que se dizia minha amiga. Comecei a ler o escrito e pensei que se tratava de uma brincadeira de mau gosto. Essa pessoa que se intitulava minha amiga dizia que o objeto que eu havia recebido era um livro amaldiçoado e que não seria bom que o lesse, pois no momento em que abrisse aquelas páginas meu destino estaria traçado e gravado ali para sempre. Julguei estar diante de uma gozação infeliz, mas, por 
outro lado, reconhecia aquele jeito de falar com as palavras. Ângela sempre soube usá-las muito bem.

Continuei a ler o bilhete.

Fiquei aterrorizada quando percebi que aquele texto realmente havia sido escrito por Ângela e, no final, ela me desejava felicidades e dizia que tudo não passava de uma curtição comigo. A data era um dia ininteligivel de junho de 2007.

Fiquei extasiada, sem saber o que pensar ou falar! Como, uma carta escrita há um ano, chega à minha casa tão misteriosamente? O que tem a ver essa correspondência com os recentes fatos ocorridos aqui em casa? Mais uma vez fiz perguntas que reverberaram no vazio de minha mente. Fiquei pasma, olhando para o nada e sem entender quais as relações possiveis entre os fatos...

Permaneci, ali, parada por um bom tempo. Aos poucos, uma imagem disforme foi se delineando melhor diante de meus olhos. Sabe quando olhamos para um objeto, mas não o vemos? Estava ali o tempo todo, mas eu estava tão contrariada que só depois de algum tempo foi que percebi a presença do livro na minha frente. Livro para o qual olhava, mas não o via...

Resolvi pegá-lo e desafiar aquela brincadeira!

Comecei a folheá-lo e achei estranho que aparecessem tantos nomes de pessoas conhecidas. Havia vários capítulos e cada um trazia como título o nome de uma personagem qualquer: Carlos, Mariana, Elizabethe, Ângela, Jorge, Flávio, Marcelo, Paulo, Sheila etc. Os 
capítulos não seguiam uma ordem alfabética, mas sim, uma cronológica. Havia datas.

Foi neste instante que, do nada, lembrei-me da súplica de Ângela: o pedido de perdão! Tomei um susto e joguei o livro para longe de mim e iniciei uma viagem por um mundo desconhecido e no qual não acreditava.

Aqueles nomes dos capítulos... Muitos eram conhecidos meus e dela, do nosso tempo de juventude. Será que todos estavam mortos como ela? Será que os nomes eram de pessoas reais ou apenas personagens de uma ficção qualquer? Será que o pedido de perdão teria relação com o livro? Será que todos os nomes ali elencados teriam tido contato com o objeto sinistro? Será que meu destino e nome ficariam também registrados naquele livro para sempre?

Balancei a cabeça e afastei os pensamentos.

Baixei e peguei o livro que havia arremessado para longe de mim.

Quando abri as páginas, todas minhas dúvidas e suspeitas começaram a desaparecer.

Agora eu parecia saber que Ângela não estava brincando! Cogitei também que o perdão era pelo fato de ela ter me enviado o livro e não ter acreditado nos poderes misteriosos dele. Todas essas imperfeitas conclusões assolaram-me quando percebi que na última parte do livro, numa folha que, acredito, talvez, não existisse antes, mas, agora, real como sou, alguma coisa havia sido escrita. Não sei se não havia notado antes devido ao susto, quando arremessei o livro para longe, ou se 
aquilo já estava escrito ali naquela página e fazia parte da brincadeira... Não sei explicar!

A única coisa concreta diante da visão que tive foi a incerteza do futuro. Um medo repentino invadiu-me como um vento forte que joga contra as paredes da casa uma janela fechada há anos...

Sentia-me como se estivesse caminhando por uma estrada deserta e ao mesmo tempo assustadora e desconhecida, repleta de seres invisiveis que sufocam a existência humana com o objetivo de fazê-los aceitar a proximidade do inevitável fim.

Surpreendi-me ao ler naquela última e derradeira folha do livro alguma coisa que se parecia com a tentativa de escrever um nome muito familiar: Carol... 